\title{
New name: Physical and Engineering Sciences in Medicine
}

Jamie Trapp ${ }^{1}$

Published online: 31 December 2019

(c) Australasian College of Physical Scientists and Engineers in Medicine 2019
As previously announced, from the current volume (Vol 43) this journal undergoes a name change to Physical and Engineering Sciences in Medicine [1]. This is the 3rd name that the journal has had, the previous being Australasian Physical Sciences in Medicine for Volumes 1-2 (1977-1979) [2] and Australasian Physical \& Engineering Sciences in Medicine for Volumes 3-42 (1980-2019). It is important to note that, although the new name will take some time to flow through to indexing databases and journal metrics, the journal itself is not new. It has been established for some 43 years as an scientific journal (Volume 1) and 60 years as an entity, in that its beginnings go back to December 1959 when it was first produced as the Australasian Newsletter of Medical Physics in 1959 [3-5].

Out of interest, Issue 1 of Australasian Newsletter of Medical Physics in 1959 contained several articles listed under Technical Notes and Progress Notes of Work in Hand, as listed in Table 1. Although these were not full articles, it can be seen that the 1959 publication was a conduit for sharing scientific information, with some of the titles similar to those seen in the current era.
Jamie Trapp

j.trapp@qut.edu.au

1 School of Chemistry and Physics, Queensland University of Technology, Brisbane, Australia 
Table 1 Titles of articles listed under technical notes and progress notes of work in hand from Australasian Newsletter of Medical Physics, 1959

\begin{tabular}{|c|c|}
\hline Title & Authors \\
\hline Plug-in H.T. Unit for use with Victoreen Condenser r-Meters Model 70 & B. Worthley, Royal Adelaide Hospital \\
\hline Radon assay system for examination of drinking water and body burden & B. Worthley, Royal Adelaide Hospital \\
\hline $\begin{array}{l}\text { High pressure ionization chamber apparatus for measuring body burden of } \gamma \text {-ray } \\
\text { emitting radioactive material }\end{array}$ & B. Worthley, Royal Adelaide Hospital \\
\hline Human body monitor & B. Worthley, Royal Adelaide Hospital \\
\hline Megavoltage Therapy & H.D. Jamieson, Wakari Hospital \\
\hline R.B.E. Measurements & H.D. Jamieson, Wakari Hospital \\
\hline Isodose curves for $4 \mathrm{MeV}$ linear accelerator & O.S. Hames, Auckland Hospital \\
\hline An Italian teleCobalt unit & C.G. Bogg, Public Hospital, Palmerston North \\
\hline The measurement of lymphatic obstruction & K.H. Clarke, Cancer Institute, Melbourne \\
\hline Assessment of dosage in heterogeneous medium & E.C. Winkler and J.O. McKay, Cancer Institute, Melbourne \\
\hline PVC ovoids for radon treatment of CA. cervix & K.L. Biggs and K. Zoethout, Cancer Institute, Melbourne \\
\hline
\end{tabular}

\section{References}

1. Trapp JV (2019) Journal name change. Australas Phys Eng Sci Med 42(3):661

2. Clarke K (1977) Australasian Physical Sciences in Medicine. Australas Phys Sci Med 1(1):2

3. Clarke K (1984) Twenty five years on. Australas Phys Eng Sci Med 7(4):140

4. Clarke K (2007) An historical perspective of the APESM. Australas Phys Eng Sci Med 30:xiv
5. Crowe SB, Kairn T (2017) Medical physics publishing in a changing research environment: the Australasian Physical \& Engineering Sciences in Medicine 40th anniversary editorial. Australas Phys Eng Sci Med 40(4):771-776

Publisher's Note Springer Nature remains neutral with regard to jurisdictional claims in published maps and institutional affiliations. 